\title{
The Interface Function of Thinking Styles between Personality and Intelligence
}

\author{
Maike Irmscher ${ }^{1, *}$ \\ ${ }^{1}$ Department of Business Administration, Economics, and Law, Carl von Ossietzky University, Oldenburg, Germany \\ *Correspondence: Department of Business Administration, Carl von Ossietzky University, Economics, and Law, \\ Ammerlaender Heerstraße 114-118, 26129 Oldenburg, Germany. E-mail: maike.irmscher@uni-oldenburg.de
}

Received: December 7, 2018

Accepted: January 8, 2019 Online Published: January 23, 2019

doi:10.5430/wje.v9n1p79

URL: https://doi.org/10.5430/wje.v9n1p79

\begin{abstract}
The aim of the present study is to investigate thinking styles at the interface between personality traits and intelligence. A total of 266 students in Germany and Austria completed the Thinking Styles Inventory for German-Speaking Samples (TSI-GER), the NEO Five-Factor Inventory (NEO-FFI) and the Intelligence-Structure Test 2000 R (I-S-T $2000 \mathrm{R}$ ). Structural equation modelling was applied to investigate whether thinking styles mediate the relationship between personality traits and intelligence. The results indicate that styles do not work as an interface between personality and intelligence, which suggests that styles represent a "stand-alone" learning prerequisite.
\end{abstract}

Keywords: thinking styles, personality traits, intelligence, structural equation modelling

\section{Introduction}

\subsection{Aim of the Study}

Individual differences in learning and constructing knowledge are investigated for decades with numerous perspectives. In differential psychology, learning prerequisites like cognitive abilities, personality traits, perseverance, self-confidence, motivation etc. have exercised researchers for a long time in order to clarify the variables determining learning potentials. Especially, the interaction between intelligence and personality is assumed to have an enormous potential to explain differences in learning outcomes (Chamorro-Premuzic \& Furnham, 2004, 2006, 2008). However, the "appearance" of the relationship between intelligence and personality is still unclear. Numerous studies try to contribute to a deeper understanding of their assumed interdependence (Ackerman \& Heggestad, 1997; Chamorro-Premuzic \& Furnham, 2004, 2006, 2008; Chamorro-Premuzic, Furnham, \& Ackerman, 2006; Chamorro-Premuzic, Moutafi, \& Furnham, 2005; Moutafi, Furnham, \& Paltiel, 2005; Reeve, Meyer, \& Bonaccio, 2006). Von Stumm, Chamorro-Premuzic, and Ackerman (2011, p. 218) as well as Reeve et al. (2006) categorize the related and involved theoretical and empirical research approaches into three perspectives. First, personality and intelligence can be viewed as separate entities with no meaningful associations. Second, an association between both constructs is assumed on a measurement level, caused by the impacts of personality on individual performance in intelligence tests; it is argued that since intellectual abilities are measured through test performances, personality traits like neuroticism are likely to affect these performances (Chamorro-Premuzic et al., 2005). The third approach considers a more developmental relationship between personality and intelligence caused by the impacts of personality on how, when, and where an individual applies, invests, and refines their cognitive abilities. Therefore, there is no consensus on the exact "appearance" of the relationship between these two constructs. However, most of the existing studies focus on a measurement level of the psychometric aspects of personality and intelligence (Chamorro-Premuzic, Furnham, \& Moutafi, 2003). This approach is supported by a large amount of empirical results referring to significant correlations between personality and intelligence measures (Ackerman \& Heggestad, 1997; Austin et al., 2002; Chamorro-Premuzic et al., 2006; Chamorro-Premuzic et al., 2005; Furnham, Moutafi, \& Chamorro-Premuzic, 2005; Moutafi et al., 2005; Reeve et al., 2006).

However, the results reported in these studies are partially inconsistent. First, intelligence and personality measures vary, making it more difficult to compare their results (Moutafi et al., 2005). Second, both personality and 
intelligence look back on a long history of disagreement about the nature of their structure, so their underlying conceptualizations vary in some parts. This leads to a difficult comparability, and even to difficulties in describing the personality-intelligence interface (Chamorro-Premuzic \& Furnham, 2006). But even if the same instruments are in fact used, the results still vary - sometimes more, sometimes less. For example, the relationships between conscientiousness (a tendency towards being systematic, meticulous, diligent and persistent) and intelligence have been found to be controversial in several studies (Ackerman \& Heggestad, 1997; Moutafi et al., 2005). What this amounts to is that the exact appearance of the personality-intelligence interface remains unclear.

Many attempts to clarify this interface have been carried out in the past. Regarding the "consensual taxonomy for understanding individual differences in personality" (Chamorro-Premuzic \& Furnham, 2006, p. 252), the Five-Factor Model of personality, three of the five major personality factors (neuroticism, extraversion, and openness to experience) show continuously significant correlations with different cognitive abilities (Moutafi et al., 2005). But as these correlations have shown inconsistent values in several studies, researchers have raised the question of whether the relationship between personality and intelligence could be mediated by other constructs. For example, Moutafi, Furnham, and Tsaousis (2006) were able to confirm that the relationship between neuroticism (which is described as a tendency to experience negative emotions) and intelligence is mediated by test anxiety. Matching these questions of mediator variables at the personality-intelligence interface, the concept of intellectual styles and, within this, the concept of thinking styles promise to provide the explanatory ability to describe this interface; thinking styles are said to be located between personality and cognitive abilities (Grigorenko \& Sternberg 1995, p. 205; Sternberg 1988, p. 218; Zhang 2013, p. 5). From an educational point of view, the investigation of thinking styles seems worthwile as they represent individual preferences in constructing knowledge and dealing with tasks (Zhang \& Sternberg, 2005). If thinking styles work as mediator variables between personality and intelligence, these styles on the one hand could help to provide the inconsistent results with a more stable and coherent structure. On the other hand, these styles could help to understand learning differences better. Supported by an impeding controversial debate on the uniqueness of the style construct (which mainly concerns whether styles are either subordinate to personality/cognitive abilities or a distinct construct), numerous studies have investigated the relationships between thinking styles and either personality or, to a lesser extent, cognitive abilities. Nevertheless, an investigation of the interface function of thinking styles is still missing (Zhang \& Sternberg, 2005). This study addresses this need for clarification and uses structural equation modelling to investigate the location of thinking styles at the interface of personality and intelligence.

\subsection{The Personality-intelligence Interface}

A debate on the characteristics of intelligence is as old as the research in this field itself (Mackintosh, 2011; Reeve \& Bonaccio, 2011). Reeve, Meyer, and Bonaccio (2006, p. 388) describe a slight consensus in the research field of intelligence. Here, intelligence and cognitive abilities are best organized into a hierarchical structure "with numerous specific abilities and skills occupying the lower levels, a small number of narrow factors at an intermediate level, and a single general factor (i.e., g) at the top" (DeYoung, 2011; Reeve \& Bonaccio, 2011; Stemmler, Hagemann, Amelang, \& Bartussek, 2011, p. 179). This hierarchy is based on the works of Spearman (1904) who proposed that intelligence consists of a general factor g: a general mental ability that supports every intellectual function and performance, and a set of specific factors s: specific mental abilities that are not shared by any other performance (Furnham et al., 2005; Rost, 2013; Stemmler et al., 2011). Continuing Spearman's work, Cattell (1943) postulated that g contains two related albeit different components: fluid (gf) and crystallized intelligence (gc) (Maltby, Day, \& Macaskill, 2011). Those two components form two general factors of intelligence which are supplied by several secondary factors (i.e., verbal or numerical abilities, figural relations etc.). Fluid intelligence gf is characterized by mental abilities independent of the cultural or socialized components of education, whereas crystallized intelligence $\mathrm{gc}$ is defined by mental abilities referring to knowledge acquired under cultural influence (Furnham et al., 2005). Within the psychometric approach regarding the personality-intelligence interface, those intellectual abilities are mostly considered as affected by personality because personality influences performance in intelligence tests (Reeve et al., 2006). For example, open-minded people are said to perform better in terms of response speed because they are more assertive (Chamorro-Premuzic \& Furnham, 2004).

In the psychometric approach, the construct of personality is mostly examined according to the Big Five Model proposed by McCrae and Costa (1987; Furnham et al., 2005). Here, the five major factors of personality (neuroticism, extraversion, openness, agreeableness, and conscientiousness) with their specific facets show differing and partly inconsistent connections to intellectual abilities. Neuroticism, a tendency to experience anxiety, stress, or nervousness, has been found to be negatively correlated with psychometric intelligence in several studies despite different correlation values (Ackerman \& Heggestad, 1997; Austin et al., 2002; Chamorro-Premuzic \& Furnham, 
2004; von Stumm et al., 2011; Zeidner \& Matthews, 2000).

The one factor of personality that has most consistently been found to be positively correlated with several cognitive abilities is openness to experience (Moutafi et al., 2005). People who are interested in new experiences and eager to learn something new show higher values in cognitive ability tests, most notably with regard to general intelligence and quantitative abilities (Kyllonen, 1997). However, different interpretations of the openness trait have led to different conceptualizations of the openness-intelligence relationships, and therefore to different results when considering the different target variables (Chamorro-Premuzic et al., 2005).

Extraversion as a tendency for conviviality and social activity has controversially been found to be both positively and negatively associated with intelligence measures (Ackerman \& Heggestad, 1997; Austin et al., 2002; Moutafi et al., 2005; von Stumm et al., 2011). It is argued that these controversial findings could be explained by the nature and design of different intelligence tests and the intellectual styles and intelligence profiles of the respondents (Moutafi et al., 2005; Robinson, 1985).

The findings on the relationships between intelligence and conscientiousness, a tendency for determination, and persistence have also been controversial (Moutafi et al., 2005). Most of the existing studies report only weak associations with intelligence (Ackerman \& Heggestad, 1997; Furnham et al., 2005; Kyllonen, 1997). Nevertheless, conscientiousness is highly correlated to academic and work performance, leading to the assumption that a relationship with cognitive abilities must in fact somehow exist (Furnham et al., 2005).

The factor which appears most unrelated to intelligence is agreeableness, which is a tendency towards altruism, compliance and cooperativeness (Furnham et al., 2005; Moutafi et al., 2005).

Several different attempts have been made to explain the inconsistent results regarding the correlations between personality traits and intellectual abilities. Some researchers suggest that the relationship of a personality trait and intelligence could be mediated by a narrow facet of this specific personality trait; this is based on the assumption that some facets of the personality trait are more strongly correlated to intellectual abilities than other facets. Furnham et al. (2005) agree that personality traits might have more distal than primal role effects. For example, the significant yet slightly inconsistent correlations between neuroticism and intelligence are arguably explained by the anxiety facet of neuroticism, which is supported for example by the study of Moutafi et al. (2006). Nevertheless, the findings on this specific association have been controversial as well (Moutafi et al., 2006). Additionally, when it comes to other personality traits, studies are either missing or have not yet been replicated to show more consistency. One of the few studies here was published by Moutafi, Furnham, and Crump (2006) who determined that the order, self-discipline and deliberation sub-facets of conscientiousness were negatively correlated with fluid intelligence.

Other researchers suggest the idea that some relationships between broad personality traits and intellectual abilities might not be linear. For example, Austin et al. (1997) posit curvilinear relations between these two constructs, while still finding a significant positive quadratic relationship between neuroticism and intelligence.

To sum up, there appears to be a need for clarification regarding the question of whether the relationship between personality and psychometric intelligence could be mediated by "something else."

The present study picks up the idea that a separate mediator variable could affect the personality-intelligence interdependencies on the measurement level. The concept of thinking styles posits them as located at the interface between personality and intelligence on a conceptual level (Grigorenko \& Sternberg 1995, p. 205; Sternberg 1988, p. 218; Zhang 2013, p. 5).

\subsection{Thinking Styles and Their Relationships to Personality and Intelligence}

Thinking styles are defined as a person's preferred ways of thinking (Sternberg, 1997). Sternberg (1997) described in his theory of mental self-government that individuals have to make decisions and set priorities to organize their thinking just like governments; they do this in a manner in which they feel most comfortable. Consequently, the different ways of thinking could be characterized as similar to different forms of government found around the world. Sternberg (1997) describes 13 thinking styles that represent the forms, functions, levels, scopes and leanings of mental self-government. Table 1 provides a short overview. 
Table 1. The Thinking Styles in the Theory of Mental Self-government (Sternberg, 1997)

\begin{tabular}{lll}
\hline Dimension & Thinking style & Individuals show a preference for ... \\
\hline Functions & Legislative & high degrees of creativity and freedom in choosing one's own strategies. \\
& Executive & $\begin{array}{l}\text { clear instructions and pre-structured tasks. } \\
\text { evaluating situations, solutions, and performances. } \\
\text { Fodicial }\end{array}$ \\
& Hierarchical & $\begin{array}{l}\text { prioritizing tasks according to one's own valuing of the tasks. } \\
\text { focusing completely on one task at a time. }\end{array}$ \\
& Monarchic & dealing with several tasks without a clear hierarchy of goals or priority. \\
& Oligarchic & working on tasks at random with flexibility on how, when and where to work. \\
& Anarchic & high levels of abstraction. \\
Levels & Global & high levels of detail. \\
& Local & working independent from others. \\
Scopes & Internal & working in groups and teams. \\
& External & curiosity in order to find a proper solution. \\
Leanings & Liberal & existing and established rules in performing tasks. \\
& Conservative &
\end{tabular}

However, this categorization has led to problems concerning its replication in empirical data. Studies investigating the factor structure of the Thinking Styles Inventories (TSI, TSI-R, TSI-R2; Sternberg, Wagner, \& Zhang, 2007) could not replicate the assumed five factors. Also, the existing studies show inconsistent results concerning the assumed factor structure of the threefold model of intellectual styles proposed by Zhang and Sternberg (2005) (see Berding, Masemann, Rebmann, and Paechter (2016) for more). Regarding this issue, Berding et al. (2016) conducted a study to validate the TSI-GER, a version of the Thinking Style Inventories for German-speaking samples. They also report problems with the structural, discriminant, and criterion validity of the questionnaire. Here they found some extremely high correlations between some thinking styles' scales, raising the question of whether the number of thinking styles postulated in the theory of mental self-government could in fact be too high. For example, the legislative style and the liberal style show high similarities both on the theoretical level as well as within a high inter-scale correlation $(\mathrm{r}=.679)$. The correlations may indicate the existence of superordinate factors combining some thinking styles into one single construct. In a further study, Berding, Irmscher, Vossmann and Gores (2018) conducted a confirmatory factor analysis which was also unable to replicate the measurement model of the TSI. This is why exploratory factor analysis was conducted in one sample and verified by means of confirmatory factor analysis in another. The TSI-GER was used in this study, and consists of 61 items. And within the four-factor solution, the number of items decreased to 46 , describing the 13 thinking styles. The results were stable and showed four consistent factors across two samples. These factors in turn combine the thinking styles into four coherent types:

- The "intrapreneurs" show preferences mainly corresponding to legislative, liberal, local, and internal thinking styles. They prefer new, creative ways of dealing with a task, like to rely on their own opinion, and like to work with details.

- The "traditionalists" prefer clear instructions and well-structured tasks. They like to work according to existing rules, and they don't like insecurity, ambiguity and novelty in dealing with tasks. Their preferences consist of executive, conservative, hierarchical, and monarchic thinking styles.

- The "conformists" show preferences according to oligarchic and anarchic thinking styles. They prefer tasks that allow the priorities set by others to be followed, or to work at random; they might not be able to assess the priority of a task themselves. This might indicate an adjustment to the perspectives of others.

- The "teamplayers" prefer tasks that allow work in groups and teams according to the external thinking style.

These four factors show comprehensible and distinctive characteristics, and therefore build the basis for the investigation within this study. The relationships between the underlying thinking styles and either personality or, to a lesser extent, cognitive abilities have been conducted by several researchers to show that styles are a distinct construct. Styles refer to preferences, whereas cognitive ability questions refer to how much and what a person is able to do (Furnham 2012; Zhang \& Sternberg, 2006). Ability levels show how efficiently an individual is able to do something, whereas styles reflect the typical propensities of an individual that show their efficiency (which varies in different situations). However, because styles refer to preferences of specific patterns of behavior, their differentiation from personality traits is far more difficult because research in personality also deals with questions of 
typical performances (Furnham, 2008; Zhang \& Sternberg, 2006). Additionally, studies concerning the relationship between thinking styles and personality on the one hand and intelligence on the other have revealed inconsistent results. For example, Zhang (2002a) identified 25 significant correlations between the 13 thinking styles and the Big Five, although only five correlations could be classified as moderate or high. The strongest correlation $(\mathrm{r}=.51)$ was found between conscientiousness and the hierarchical style; and moderate correlations were found between openness and the legislative style as well as the liberal style, neuroticism and conservative styles; and between extraversion and the external style. A later study by Zhang (2006) revealed that conscientiousness is a strong predictor of the legislative, executive, internal, external, hierarchical, and monarchic styles.

Grigorenko and Sternberg (1997) found a significant correlation between the "leanings" thinking styles and creativity components of intelligence measured by the Sternberg Triarchic Abilities Test. Far more studies report significant yet inconsistent correlations between thinking styles and academic performance, which have led researchers in this field to the conclusion that there is indeed a relationship between thinking styles and (academic) abilities (Bernardo, Zhang, \& Callueng 2002; Cano-Garcia \& Hewitt Hughes, 2000; Grigorenko \& Sternberg, 1997; Zhang, 2001, 2002b, 2004; Zhang \& Sternberg, 2000).

There is a lack of studies investigating the relationships between thinking styles and personality as well as intelligence. As a result, the "interface function" of styles between personality and intelligence postulated within the theory of mental self-government has so far not been clarified. Zhang (2013, p.7) points out how "Undoubtedly, confusion over the relationship of styles to ability/intelligence and personality slowed down research activities in the area of styles for some time." This study addresses this gap and uses structural equation modelling to investigate whether thinking styles reflected by the four types found by Berding et al. (2018) are located between personality traits and intelligence on an empirical level.

\section{Method}

\subsection{Participants}

Two hundred and sixty-six students from three universities in Germany and Austria took part in this study. 72 were male and 194 were female, with an age range between 18 to 47 years and a mean of 25.95 years $(\mathrm{SD}=4.513)$. The majority of the participants were studying to become teachers $(54.9 \%) .41 .0 \%$ of the participants were studying psychology (4.1\% missing cases). All participants voluntarily responded to the NEO-FFI, the I-S-T $2000 \mathrm{R}$ and the TSI-GER at their respective universities in the presence of the author or their teacher.

\subsection{Measures}

The personality traits were evaluated with the NEO Five-Factor Inventory (NEO-FFI) based on Costa and McCrae in a German version (Borkenau \& Ostendorf, 1993). This inventory consists of 60 items measuring the five traits of neuroticism, extraversion, openness to experience, conscientiousness and agreeableness. Each item of the test is a statement to which the participant responds on a five-point Likert scale ranging from 1 (strongly disagree) to 5 (strongly agree). A considerable amount of research has been done on this instrument, finding that it demonstrates high levels of reliability and validity (Lüdtke, Trautwein, Nagy, \& Köller, 2004). In the present study, Cronbach's alpha coefficients of the five dimensions are .715 (neuroticism), .591 (extraversion), .510 (openness), .753 (agreeableness), and .654 (conscientiousness).

The Intelligence-Structure Test 2000 R (I-S-T 2000 R) by Liepmann, Beauducel, Brocke, and Amthauer (2007) was used to evaluate the intelligence scores of the participants. This is a timed test which allows an evaluation of the verbal, numerical, and figural abilities of the participants, as well as their reasoning ability and their fluid and crystallized intelligence. This test is one of the most-used in the German-speaking world (Maltby et al., 2011; Stemmler et al., 2011). The test modules applied in this study contain a total of 264 tasks; the first 180 of these are split into nine groups with 20 tasks each where the students had to complete as many of them as they could within a certain period of time. These tasks measure verbal, figural, and numerical abilities as well as reasoning ability. 84 subsequent tasks are designed as selection tasks, and must be answered in 40 minutes; these aim to reflect fluid and crystallized intelligence. The test manual provides evidence of the test's reliability (alpha coefficients ranging from .87 to .96 ).

The Thinking Styles Inventory for German-speaking samples (TSI-GER) was used for the measurement of the thinking styles (Berding et al., 2016). This consists of 61 items assessing the 13 thinking styles proposed in Sternberg's theory of mental self-government (1997). Individuals assess how well an item describes their behavior on a seven-point Likert scale ranging from 1 (not at all well) to 7 (extremely well). High values indicate a high 
preference for a certain thinking style. In the present study, Cronbach's alpha coefficients of the four types are .919 (intrapreneurs), .855 (traditionalists), .766 (conformists), and .884 (teamplayers).

\subsection{Structural Model}

A simplified structural model for this study is shown in Figure 1. It represents the aim of the study which is to investigate whether thinking styles reflected by the four types found by Berding et al. (2018) are located between personality traits and psychometric intelligence on an empirical level.

intrapreneurs (in)

traditionalists (tr)

conformists (conf)

teamplayers (te)

neuroticism (ne)

extraversion (ex)

openness $(o p)$

conscientiousness (cons)

agreeableness $(\mathrm{ag})$

\author{
verbal intelligence (vi) \\ numerical intelligence $(n i)$ \\ figural intelligence (fi) \\ reasoning (re) \\ fluid intelligence $(g f)$
}

crystallized intelligence $(g c)$

Figure 1. A Simplified Structural Model of Types of Styles Mediating the Personality-intelligence Interface

\section{Results}

\subsection{Application of CFA Using Four Types of Thinking Styles}

Although the study by Berding et al. (2016) was able to provide the TSI-R2 for German-speaking samples with a stable factor structure, the empirical data provided in international studies concerning the validity and reliability of the TSI-R2 remain contradictory (see Berding et al. (2016) for further details). Against this background, confirmatory factor analysis (CFA) was deployed to examine whether the measurement model of the TSI-GER adequately describes the thinking styles in this study sample. The distribution attributes of the items will be reported before conducting the CFA below.

Skew does not exceed the absolute value of 1.206, and kurtosis does not exceed the absolute value of 2.156. They are within the acceptable range for a moderate violation of normal distribution $(\mid$ skew $|<2$,$| kurtosis \mid<7)$ and allow the application of the maximum likelihood algorithm (Reinecke 2014; West, Finch, \& Curran, 1995). However, the implementation of CFA showed similar problems found in the study by Berding et al. (2018): the latent variable covariance matrix was not positive definite, so the measurement model could not be confirmed by the data. A CFA based on the four types found by Berding et al. (2018) with 244 evaluable cases showed acceptable values, indicating a global model fit: $\chi^{2}(983)=2474.831, \mathrm{p}<.01$; RMSEA: .079; RMSEA-CI90 [.075; .083]; SRMR: .106; CFI: .717 (Bühner, 2011; Heene, Hilbert, Draxler, Ziegler, \& Bühner, 2011; Kline, 2016). Table 2 shows the means and standard deviations of the four types of thinking styles.

Table 2. Means and Standard Deviations of the Four Types of Thinking Styles

\begin{tabular}{ccc}
\hline Type of styles & Mean & Standard deviation \\
\hline Intrapreneurs & 4.464 & .767 \\
Traditionalists & 5.269 & .826 \\
Conformists & 3.400 & .888 \\
Teamplayers & 5.208 & 1.110 \\
\hline
\end{tabular}


In summary, the results of the CFA indicate that the model of four types of thinking styles enables their further application.

\subsection{Are Thinking Styles Located at the Personality-intelligence Interface?}

Regarding the NEO-FFI, skew does not exceed the absolute value of 1.312, and kurtosis does not exceed the absolute value of 1.845 . They are within the range for a moderate violation of normal distribution $(\mid$ skew $|<2$,$| kurtosis \mid<7)$ and allow the application of the maximum likelihood algorithm (Reinecke 2014; West et al., 1995). The absolute values of skew and kurtosis concerning the I-S-T $2000 \mathrm{R}$ also are within this range (skew does not exceed .343, and kurtosis does not exceed .710). The number of evaluable observations is 244 for the calculation of the structural equation model. Figure 2 shows the structural model underlying the further calculation.

The results of the calculation will be presented in the tables below to improve readability.

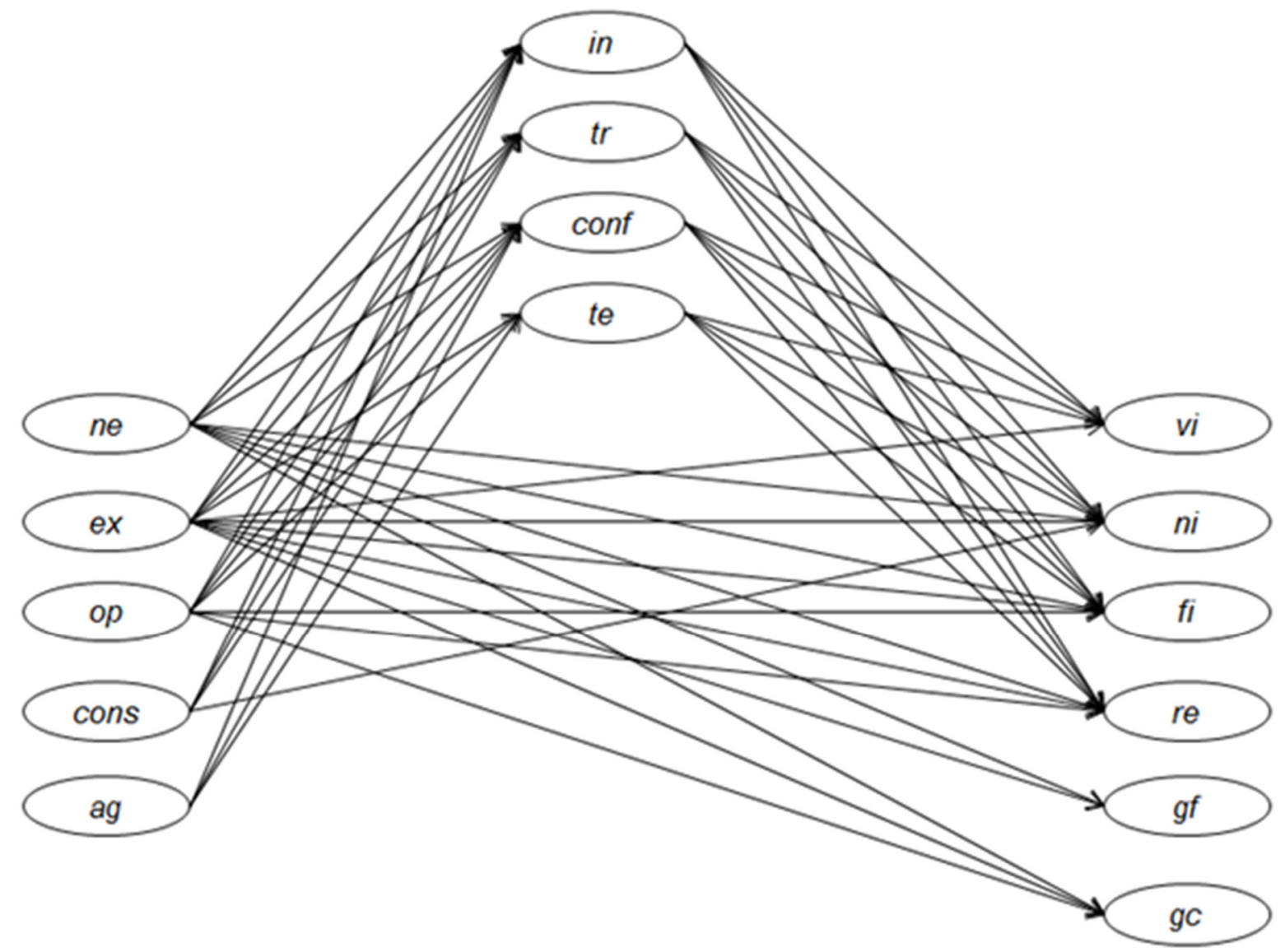

Figure 2. Structural Model of Analyzed Paths regarding the Location of Thinking Styles at the Personality-intelligence Interface

Notes: ne = neuroticism; ex = extraversion; op = openness; cons = conscientiousness; ag = agreeableness (Borkenau \& Ostendorf, 1993); in = intrapreneurs; $\operatorname{tr}=$ traditionalists; conf = conformists; te = teamplayers (Berding et al., 2018); $\mathrm{vi}=$ verbal intelligence; $\mathrm{ni}=$ numerical intelligence; $\mathrm{fi}=$ figural intelligence; $\mathrm{re}=$ reasoning; $\mathrm{gf}=$ fluid intelligence; $\mathrm{gc}=$ crystallized intelligence (Liepmann et al., 2007).

Because of the lack of related studies investigating the interface function of thinking styles between personality and intelligence, only the paths that could be interpreted in advance on a theoretical level were investigated. Intrapreneurs are characterized as open-minded, creative, trusting in themselves and detail-loving in their preferences when dealing with tasks. So it is plausible to assume that neuroticism, extraversion and agreeableness show negative correlations to this type of style, whereas openness and conscientiousness show positive correlations to this type. Traditionalists like to work on pre-structured tasks with clear instructions that allow focusing on one thing at a time. 
So these people might show high degrees of neuroticism and conscientiousness, whereas the correlations to extraversion and openness might be negative. The connection to agreeableness is unclear; it might be possible that traditionalists like to work with others because of their insecurity in new tasks, but is also seems plausible to assume that traditionalists don't like to work with others because the opinions of others could cause insecurity with them. Because conformists like to work on tasks that allow them to adjust their techniques to others (which is indicated by a possible lack of ability to set priorities by themselves), a positive correlation to neuroticism, extraversion and agreeableness seems plausible, along with negative correlations with openness and conscientiousness. Teamplayers show preferences to work with others, so positive correlations with extraversion, openness and agreeableness are interpretable. But because they show no other preference, it is not possible to describe the relations to neuroticism and conscientiousness, because here both positive and negative correlations could be assumed.

The paths between the four types of styles and intelligence measures were also interpreted in advance on a theoretical level. Due to the design of the intelligence test, it is assumed that intrapreneurs show positive correlations to verbal, numerical, and figural intelligence as well as to reasoning because they show preferences to rely on their own opinion, to work with details, and to be creative. All of these preferences are enabled by the test conditions. The correlations between both traditionalists and conformists and the intelligence measures mentioned are assumed to be negative because the timed test with unusual tasks that do not contain any guidance for solving them could impede those performing them. As all of the intelligence test tasks have to be solved independently, the correlations between the teamplayer type and the intelligence measures are assumed to be negative because none of the tasks allow another person to help solve them. The testing conditions for measuring ge and gf did not allow secure prediction of positive or negative correlations, which is why these paths were not considered in the calculation.

Regarding the relationships between the personality traits and the psychometric intelligence variables, only the corresponding significant relationships found by Ackerman and Heggestad (1997) were considered; their study summarizes the most consensual results.

Table 3 shows the means and standard deviations for the NEO-FFI and the I-S-T $2000 \mathrm{R}$.

Table 3. Means and Standard Deviations of the Personality and Intelligence Measures

\begin{tabular}{lrc}
\hline Personality traits & Mean & Standard deviation \\
\hline Neuroticism & 2.742 & .512 \\
Extraversion & 3.395 & .430 \\
Openness & 3.080 & .451 \\
Conscientiousness & 3.417 & .578 \\
Agreeableness & 3.700 & .461 \\
\hline IQ scores & & \\
\hline Verbal intelligence & 100.398 & 12.252 \\
Numerical intelligence & 98.350 & 13.766 \\
Figural intelligence & 98.287 & 13.606 \\
Reasoning & 100.277 & 12.358 \\
Fluid intelligence & 105.804 & 11.342 \\
Crystallized intelligence & 104.119 & 11.534 \\
\hline
\end{tabular}

Regarding the structural equation modelling, a CFA was employed to test for global and local model fit. The results showed adequate values concerning a global model fit: $\chi^{2}(32)=84.748, \mathrm{p}<.01$; RMSEA: .079; RMSEA-CI90 [.059; .099]; SRMR: .056; CFI: 965 (Bühner, 2011; Heene et al., 2011; Kline, 2016). The calculation concerning a local model fit was less satisfactory; Table 4 shows the standardized regression coefficients of the investigated relations. 
Table 4. Standardized Regression Coefficients

\begin{tabular}{|c|c|c|}
\hline & Regression coefficient & Two-tailed p-value \\
\hline \multicolumn{3}{|l|}{ Verbal intelligence } \\
\hline Extraversion & -.110 & .059 \\
\hline Intrapreneurs & .098 & .106 \\
\hline Traditionalists & .037 & .442 \\
\hline Conformists & -.083 & .130 \\
\hline Teamplayers & .005 & .923 \\
\hline \multicolumn{3}{|c|}{ Numerical intelligence } \\
\hline Neuroticism & -.062 & .296 \\
\hline Extraversion & -.068 & .285 \\
\hline Conscientiousness & .005 & .792 \\
\hline Intrapreneurs & -.044 & .224 \\
\hline Traditionalists & .005 & .874 \\
\hline Conformists & .009 & .774 \\
\hline Teamplayers & -.042 & .238 \\
\hline \multicolumn{3}{|l|}{ Figural intelligence } \\
\hline Neuroticism & -.054 & .377 \\
\hline Extraversion & -.226 & .000 \\
\hline Openness & .072 & .052 \\
\hline Intrapreneurs & -.058 & .349 \\
\hline Traditionalists & -.097 & .086 \\
\hline Conformists & .043 & .369 \\
\hline Teamplayers & .097 & .054 \\
\hline \multicolumn{3}{|l|}{ Reasoning } \\
\hline Neuroticism & -.066 & .190 \\
\hline Extraversion & -.176 & .004 \\
\hline Openness & .029 & .147 \\
\hline Intrapreneurs & -.013 & 619 \\
\hline Traditionalists & -.018 & .363 \\
\hline Conformists & .009 & .678 \\
\hline Teamplayers & .017 & .498 \\
\hline \multicolumn{3}{|l|}{$\mathrm{gc}$} \\
\hline Neuroticism & -.044 & .570 \\
\hline Extraversion & -.148 & .061 \\
\hline Openness & .173 & .006 \\
\hline \multicolumn{3}{|l|}{ gf } \\
\hline Neuroticism & -.068 & .250 \\
\hline Extraversion & -.161 & .010 \\
\hline \multicolumn{3}{|l|}{ Intrapreneurs } \\
\hline Neuroticism & -.194 & .004 \\
\hline Extraversion & .098 & .178 \\
\hline Openness & .118 & .075 \\
\hline Agreeableness & -.318 & .000 \\
\hline Conscientiousness & .083 & .193 \\
\hline \multicolumn{3}{|l|}{ Traditionalists } \\
\hline Neuroticism & .105 & .114 \\
\hline Extraversion & -.140 & .027 \\
\hline Openness & -.048 & .449 \\
\hline Conscientiousness & .209 & .002 \\
\hline \multicolumn{3}{|l|}{ Conformists } \\
\hline Neuroticism & .076 & .243 \\
\hline Extraversion & -.039 & .597 \\
\hline Openness & -.006 & .928 \\
\hline Agreeableness & .060 & .450 \\
\hline Conscientiousness & -.015 & .827 \\
\hline \multicolumn{3}{|l|}{ Teamplayers } \\
\hline Extraversion & .262 & .000 \\
\hline Openness & .046 & .489 \\
\hline Agreeableness & -.070 & .321 \\
\hline
\end{tabular}


As can be seen in Table 4, only a few correlations are significant, indicating that a local model fit is not achieved.

Table 5 shows the direct and indirect effects of the variables and paths considered.

Table 5. Direct and Indirect Effects between Personality, Types of Styles, and Intelligence

\begin{tabular}{|c|c|c|c|c|c|c|c|c|c|c|c|c|c|c|c|}
\hline $\begin{array}{l}\text { Effects } \\
\text { from... }\end{array}$ & $\begin{array}{l}\text { ne } \\
\text { to ni }\end{array}$ & $\begin{array}{l}\text { ne } \\
\text { to fi }\end{array}$ & $\begin{array}{l}\text { ne } \\
\text { to re }\end{array}$ & $\begin{array}{l}\text { ne } \\
\text { to } g f\end{array}$ & $\begin{array}{l}\text { ne } \\
\text { to gc }\end{array}$ & $\begin{array}{l}\text { ex } \\
\text { to vi }\end{array}$ & $\begin{array}{l}\text { ex } \\
\text { to ni }\end{array}$ & $\begin{array}{l}\text { ex } \\
\text { to fi }\end{array}$ & $\begin{array}{l}\text { ex } \\
\text { to re }\end{array}$ & $\begin{array}{l}\text { ex } \\
\text { to gf }\end{array}$ & $\begin{array}{l}\text { ex } \\
\text { to gc }\end{array}$ & $\begin{array}{l}\text { op } \\
\text { to fi }\end{array}$ & $\begin{array}{l}\text { op } \\
\text { to re }\end{array}$ & $\begin{array}{l}\text { op } \\
\text { to gc }\end{array}$ & $\begin{array}{l}\text { cons } \\
\text { to ni }\end{array}$ \\
\hline total & -1.412 & -1.348 & -1.574 & -1.525 & -.978 & -2.847 & -2.706 & $-6.267 *$ & $-4.940 *$ & -4.287 & -3.929 & 2.287 & .809 & $4.388^{*}$ & .061 \\
\hline total indirect & .263 & .119 & .032 & --- & --- & .254 & -.525 & 1.020 & .151 & --- & --- & .060 & .001 & --- & -.079 \\
\hline \multicolumn{16}{|c|}{ specific indirect (mediated by type of style ...) } \\
\hline in & .229 & .306 & .061 & --- & --- & .270 & -.138 & -.183 & -.036 & --- & --- & -.211 & -.042 & --- & -.109 \\
\hline $\operatorname{tr}$ & .015 & -.275 & -.045 & --- & --- & -.146 & -.024 & .437 & .072 & --- & --- & .143 & .024 & --- & .034 \\
\hline conf & .019 & .088 & .016 & --- & --- & .092 & -.011 & -.054 & -.010 & --- & --- & -.008 & -.001 & --- & -.004 \\
\hline te & --- & --- & --- & --- & --- & .038 & -.351 & .820 & .125 & --- & --- & .137 & .021 & --- & --- \\
\hline direct & -1.675 & -1.467 & -1.606 & -1.525 & -.978 & -3.101 & -2.181 & $-7.287^{*}$ & $-5.090 *$ & -4.287 & -3.929 & 2.226 & .808 & $4.388^{*}$ & .140 \\
\hline
\end{tabular}

Notes: ne=neuroticism; ex=extraversion; op=openness; cons=conscientiousness; ag =agreeableness (Borkenau \& Ostendorf, 1993); in = intrapreneurs; $\operatorname{tr}=$ traditionalists; conf=conformists; te=teamplayers (Berding et al., in press); vi=verbal intelligence; ni=numerical intelligence; $\mathrm{fi}$ = figural intelligence; $\mathrm{re}=$ reasoning; $\mathrm{gf}=$ fluid intelligence; $\mathrm{gc}=$ crystallized intelligence (Liepmann et al., 2007)

$* \mathrm{p}<.05$

As Table 5 shows, none of the considered indirect effects of the four types of styles on the relationships between personality and intelligence becomes significant. For example, the study revealed a significant negative effect from extraversion to figural intelligence. But this effect is a direct one: it is not mediated by any of the four types of styles.

\section{Discussion}

The aim of the present study was to investigate whether thinking styles work as a mediator variable between intelligence and personality to examine their "interface function". The results showed that no indirect effects of thinking styles on the relationships between personality traits and intelligence became significant, so the "interface function" of thinking styles as proposed by Grigorenko and Sternberg (1995, p. 205), Sternberg (1988, p. 218), and Zhang (2013, pp. 5) could not be replicated by empirical data within this study. This can be critically interpreted in several ways. For one thing, the study sample was relatively homogenous, with only students from either teacher education or psychology programs being interviewed. With this in mind, the possibility of different results coming from different samples cannot be ruled out. Secondly, considering the variety of existing intelligence and style measures, the results could be different when using other measures with different operationalizations of the variables. Additionally, the few unconsidered paths could show unexpected estimates. And from a more theoretical point of view, due to the cross-sectional design of the study, developmental effects of the variables are blended out because the measures used in this study only reflect "snapshots." Nevertheless, the fact that no indirect effects of the four types of styles on the relationships between personality and intelligence could be found achieves important conclusions. Considering the results of Berding et al. (2018) or Berding et al. (2016), who had difficulties replicating the structure of styles postulated within the theory of mental self-government (Sternberg, 1997) or within the threefold model of intellectual styles (Zhang \& Sternberg, 2005), further research to clarify the "style construct" could support a broader understanding of the differences in individual preferences when dealing with tasks. Nevertheless, the results of this study indicate that styles represent a stand-alone learning prerequisite which leads to the implication that preferences in dealing with tasks are independent from specific levels of cognivite abilities and personality traits. Thus, educators who are interested in addressing the preferences of their learners do not have to take their cognitive abilities or their personality traits into account necessarily.

\section{References}

Ackerman, P. L., \& Heggestad, E. D. (1997). Intelligence, personality, and interests: Evidence for overlapping traits. Psychological Bulletin, 121(2), 219-245. https://doi.org/10.1037//0033-2909.121.2.219

Austin, E. J., Deary, I. J., \& Gibson, G. J. (1997). Relationships between ability and personality: three hypotheses tested. Intelligence, 25(1), 49-70. https://doi.org./10.1016/S0160-2896(97)90007-6

Austin, E. J., Deary, I. J., Whiteman, M. C., Fowkes, F. G. R., Pedersen, N. L., Rabbitt, P., Bent, N., \& McInnes, L. 
(2002). Relationships between ability and personality: does intelligence contribute positively to personal and social adjustment? Personality and Individual Differences, 32(8), 1391-1411. https://doi.org/10.1016/S0191-8869(01)00129-5

Berding, F., Irmscher, M., Vossmann, M., \& Gores, A. (2018). Berufliches Handeln in der Digitalisierung Sichtweisen auf Wissen und Präferenzen im Umgang mit beruflichen Aufgaben von kaufmännischen Auszubildenden. Zeitschrift für Berufs- und Wirtschaftspädagogik, 114(2), 213-246.

Berding, F., Masemann, M., Rebmann, K., \& Paechter, M. (2016). Perspectives on the validity of the Thinking Styles Inventories. World Journal of Education, 6(6), 69-82. https://doi.org/10.5430/wje.v6n6p69

Bernardo, A. B. I., Zhang, L. F., \& Callueng, C. M. (2002). Thinking styles and academic achievement among Filipino students. The Journal of Genetic Psychology, 163(2), 149-163. https://doi.org/10.1080/00221320209598674

Borkenau, P., \& Ostendorf, F. (1993). NEO-Fünf-Faktoren Inventar (NEO-FFI) nach Costa und McCrae. Handanweisung. Göttingen: Hogrefe.

Bühner, M. (2011). Einführung in die Test- und Fragebogenkonstruktion (3rd ed.). München: Pearson.

Cano-Garcia, F., \& Hewitt Hughes, E. (2000). Learning and thinking styles: An analysis of their interrelationship and influence on academic performance. Educational Psychology, 20(4), 413-430. https://doi.org/10.1080/713663755

Cattell, R. (1943). The measurement of adult intelligence. Psychological Bulletin, 40(3), 153-193. https://doi.org/10.1037/h0059973

Chamorro-Premuzic, T., \& Furnham, A. (2004). A possible model for understanding the personality-intelligence interface. British Journal of Psychology, 95(2), 249-264. https://doi.org/10.1348/000712604773952458

Chamorro-Premuzic, T., \& Furnham, A. (2006). Intellectual competence and the intelligent personality: A third way in differential psychology. Review of General Psychology, 10(3), 251-267. https://doi.org/10.1037/1089-2680.10.3.251

Chamorro-Premuzic, T., \& Furnham, A. (2008). Personality, intelligence and approaches to learning as predictors of academic performance. Personality and Individual Differences, 44(7), 1596-1603. https://doi.org/10.1016/j.paid.2008.01.003

Chamorro-Premuzic, T., Furnham, A., \& Ackerman, P. L. (2006). Ability and personality correlates of general knowledge. Personality and Individual Differences, 41(3), 419-429. https://doi.org/10.1016/j.paid.2005.11.036

Chamorro-Premuzic, T., Furnham, A., \& Moutafi, J. (2003). The relationship between estimated and psychometric personality and intelligence scores. Journal of Research in Personality, 38(5), 505-513. https://doi.org/10.1016/j.jrp.2003.10.002

Chamorro-Premuzic, T., Moutafi, J., \& Furnham, A. (2005). The relationship between personality traits, subjectively-assessed and fluid intelligence. Personality and Individual Differences, 38(7), 1517-1528. https://doi.org/10.1016/j.paid.2004.09.018

DeYoung, C. G. (2011). Intelligence and personality. In R. J. Sternberg \& S. B. Kaufman (Eds.), The Cambridge handbook of intelligence (pp. 711-737). Cambridge: Cambridge University Press.

Furnham, A. (2008). Personality and intelligence at work. Exploring and explaining individual differences at work. New York, NY: Routledge.

Furnham, A. (2012). Intelligence and intellectual styles. In L. F. Zhang, R. J. Sternberg \& S. Rayner (Eds.), Handbook of intellectual styles. Preferences in cognition, learning, and thinking (pp. 173-192). New York, NY: Springer Publishing Company.

Furnham, A., Moutafi, J., \& Chamorro-Premuzic, T. (2005). Personality and intelligence: gender, the Big Five, self-estimated and psychometric intelligence. International Journal of Selection and Assessment, 13(1), 11-24. https://doi.org/10.1111/j.0965-075X.2005.00296.x

Grigorenko, E. L., \& Sternberg, R. J. (1997). Styles of thinking, abilities, and academic performance. Exceptional Children, 63(3). 295-312. https://doi.org/10.1177/001440299706300301

Grigorenko, E. L., \& Sternberg, R. J. (1995). Thinking styles. In D. H. Saklofske \& M. Zeidner (Eds.), International handbook of personality and intelligence (pp. 205-229). New York, NY: Plenum Press. 
Heene, M., Hilbert, S., Draxler, C., Ziegler, M., \& Bühner, B. (2011). Masking misfit in confirmatory factor analysis by increasing unique variances: A cautionary note on the usefulness of cutoff values of fit indices. Psychological Methods, 16(3), 319-336. https://doi.org/10.1037/a0024917

Kline, R. B. (2016). Principles and practice of structural equation modeling (4th ed.). New York, NY: The Guilford Press.

Kyllonen, P. (1997). Smart testing. In R. F. Dillon (Ed.), Handbook on testing (pp. 347-368). Westport, CT: Greenwood Press.

Liepmann, D., Beauducel, A., Brocke, B., \& Amthauer, R. (2007). I-S-T 2000 R. Intelligenz-Struktur-Test 2000 R. Manual (2nd ed.). Göttingen: Hogrefe.

Lüdtke, O., Trautwein, U., Nagy, G., \& Köller, O. (2004). Eine Validierungsstudie zum NEO-FFI in einer Stichprobe junger Erwachsener. Diagnostica, 50(3), 134-144. https://doi.org./10.1026/0012-1924.50.3.134

Mackintosh, N. J. (2011). History of theories and measurement of intelligence. In R. J. Sternberg \& S. B. Kaufman (Eds.), The Cambridge handbook of intelligence (pp. 3-19). Cambridge: Cambridge University Press.

Maltby, J., Day, L., \& Macaskill, A. (2011). Differentielle Psychologie, Persönlichkeit und Intelligenz (2nd ed.). München: Pearson.

McCrae, R., \& Costa, P. (1987). Validation of the five-factor model of personality across instruments and observers. Journal of Personality and Social Psychology, 52(1), 81-90. https://doi.org./10.1037/0022-3514.52.1.81

Moutafi, J., Furnham, A., \& Crump, J. (2006). What facets of openness and conscientiousness predict fluid intelligence score? Learning and Individual Differences, 16(1), 31-42. https://doi.org/10.1016/j.lindif.2005.06.003

Moutafi, J., Furnham, A., \& Paltiel, L. (2005). Can personality factors predict intelligence? Personality and Individual Differences, 38(5), 1021-1033. https://doi.org/10.1016/j.paid.2004.06.023

Moutafi, J., Furnham, A., \& Tasousis, I. (2006). Is the relationship between intelligence and trait neuroticism mediated by test anxiety? Personality and Individual Differences, 40(3), 587-597. https://doi.org/10.1016/j.paid.2005.08.004

Reeve, C. L., \& Bonaccio, S. (2011). The nature and structure of "intelligence". In T. Chamorro-Premuzic, S. von Stumm, \& A. Furnham (Eds.), The Wiley-Blackwell handbook of individual differences (pp. 187-216). Chichester: Wiley \& Sons.

Reeve, C. L., Meyer, R. D., \& Bonaccio, S. (2006). Intelligence-personality associations reconsidered: the importance of distinguishing between general and narrow dimensions of intelligence. Intelligence, 34(4), 387-402. https://doi.org/10.1016/j.intell.2005.11.001

Reinecke, J. (2014). Strukturgleichungsmodelle in den Sozialwissenschaften (2nd ed.). München: Oldenbourg.

Robinson, D. L. (1985). How personality relates to intelligence test performance: implications for a theory of intelligence, ageing research, and personality assessment. Personality and Individual Differences, 6(2), 203-216. https://doi.org/10.1016/0191-8869(85)90110-2

Rost, D. H. (2013). Handbuch Intelligenz. Weinheim: Beltz.

Spearman, C. (1904). "General intelligence", objectively determined and measured. American Journal of Psychology, 15(2), 201-293. https://doi.org/10.2307/1412107

Stemmler, G., Hagemann, D., Amelang, M., \& Bartussek, D. (Eds.) (2011). Differentielle Psychologie und Persönlichkeitsforschung (7th ed.). Stuttgart: Kohlhammer.

Sternberg, R. J. (1988). Mental self-government: A theory of intellectual styles and their development. Human Development, 31(4), 197-221. https://doi.org./10.1159/000275810

Sternberg, R. J. (1997). Thinking styles. Cambridge: Cambridge University Press.

Sternberg, R. J., Wagner, R. K., \& Zhang, L. F. (2007). Thinking Styles Inventory-Revised II. Unpublished test, Tufts University.

Stumm, S., Chamorro-Premuzic, T., \& Ackerman, P. L. (2011). Re-visiting intelligence-personality associations. Vindicating intellectual investment. In T. Chamorro-Premuzic, S. von Stumm, \& A. Furnham (Eds.), The Wiley-Blackwell handbook of individual differences (pp. 217-241). Chichester: Wiley \& Sons. 
West, S. G., Finch, J. F., \& Curran, P. J. (1995). Structural equation models with nonnormal variables. In R. H. Hoyle (Ed.), Structural equation modeling (pp. 56-75). Thousand Oaks: Sage.

Zeidner, M., \& Matthews, G. (2000). Intelligence and personality. In R. J. Sternberg (Ed.), Handbook of intelligence (pp. 581-610). New York, NY: Cambridge University Press.

Zhang, L. F. (2001). Do thinking styles contribute to academic achievement beyond self-rated abilities? The Journal of Psychology, 135(6), 621-637. https://doi.org/10.1080/00223980109603724

Zhang, L. F. (2002a). Thinking styles and the Big Five personality traits. Educational Psychology, 22(1), 17-31. https://doi.org/10.1080/01443410120101224

Zhang, L. F. (2002b). Thinking styles: Their relationship with modes of thinking and academic performance. Educational Psychology, 22(3), 331-348. https://doi.org/10.1080/01443410220138557

Zhang, L. F. (2004). Revisiting the predictive power of thinking styles for academic performance. Journal of Psychology: Interdisciplinary and Applied, 138(4), 351-370. https://doi.org/10.3200/JRLP.138.4.351-370

Zhang, L. F. (2006). Thinking styles and the Big Five personality traits revisited. Personality and Individual Differences, 40(6), 1177-1187. https://doi.org/10.1016/j.paid.2005.10.011

Zhang, L. F. (2013). The malleability of intellectual styles. New York, NY: Cambridge University Press.

Zhang, L. F., \& Sternberg, R. J. (2000). Are learning approaches and thinking styles related? A study in two Chinese populations. The Journal of Psychology, 134(5), 469-489. https://doi.org/10.1080/00223980009598230

Zhang, L. F., \& Sternberg, R. J. (2005). A threefold model of intellectual styles. Educational Psychology Review, 17(1), 1-53. https://doi.org/10.1007/s10648-005-1635-4

Zhang, L. F., \& Sternberg, R. J. (2006). The nature of intellectual styles. London: Lawrence Erlbaum Associates. 